\title{
Precipitation of spherical boehmite from concentrated sodium aluminate solution by adding gibbsite as seed
}

\author{
Gui-hua Liu, Zheng Li, Xiao-bin Li, Tian-gui Qi, Zhi-hong Peng, and Qiu-sheng Zhou \\ School of Metallurgy and Environment, Central South University, Changsha 410083, China \\ (Received: 19 September 2016; revised: 17 April 2017; accepted: 20 April 2017)
}

\begin{abstract}
The precipitation of spherical boehmite was studied by surface energy calculations, measurements of precipitation ratios, Fourier transform infrared spectroscopy, X-ray diffraction, scanning electron microscopy, and transmission electron microscopy. The surface energy calculation results show that the (001) and (112) planes of gibbsite surfaces are remarkably stable because of their low surface energies. In addition, the (010) plane of boehmite grows preferentially during precipitation because of its low surface energy. Thus, we propose a method to precipitate spherical boehmite from a supersaturated sodium aluminate solution by adding gibbsite as seed in a heterogeneous system. In this method, gibbsite acts as the preliminary seed and saturation modifier. The results show that the fine boehmite first nucleates on the (001) and (112) planes of gibbsite and then grows vertically on the (001) and (112) basal planes of gibbsite via self-assembly, thereby forming spherical boehmite. Simultaneously, gibbsite is dissolved into the aluminate solution to maintain the saturation for the precipitation of boehmite. The precipitation ratio fluctuates (forming an M-shaped curve) because of gibbsite dissolution and boehmite precipitation. The mechanism of boehmite precipitation was further discussed on the basis of the differences in surface energy and solubility between gibbsite and boehmite. This study provides an environmentally friendly and economical method to prepare specific boehmite in a heterogeneous system.
\end{abstract}

Keywords: precipitation; sodium aluminate solution; morphology; boehmite; gibbsite; surface energy

\section{Introduction}

Boehmite $(\gamma-\mathrm{AlOOH})$ is a significant intermediate hydrated alumina that can maintain its shape during transformation to transition alumina $\left(\gamma-, \delta\right.$-, and $\left.\theta-\mathrm{Al}_{2} \mathrm{O}_{3}\right)$ or $\alpha-\mathrm{Al}_{2} \mathrm{O}_{3}$. For example, the flower-like, hollow, nanowire, or porous-ball transition alumina is often used as a carrier for catalysts [1] and medicines [2] and as thin films and adsorbents [3]. Ball-like, bar-like, and plate-like $\alpha-\mathrm{Al}_{2} \mathrm{O}_{3}$ are widely used as heat-insulating materials and as reinforcements for composites [4]. Moreover, alumina is also used for dental materials or orthopedic devices because of its good biocompatibility [5-6]. Thus, the synthesis of boehmite with a given morphology has attracted considerable interest.

Two main routes are usually used to prepare boehmite $\mathrm{Al}\left(\mathrm{NO}_{3}\right)_{3}$, or $\mathrm{NaAlO}_{2}$ is often used to prepare nanofiber [7], nanowire [8-9], nanorod [10], nanoribbon [11-12], or nawith a specific morphology: (1) $\mathrm{Al}_{2}\left(\mathrm{SO}_{4}\right)_{3}, \mathrm{AlCl}_{3}$,

nosheet [13] boehmite via neutralization or hydrolysis, and (2) aluminum alkoxide is extensively used to synthesize boehmite or pseudoboehmite with the specific morphology via hydrolysis. Moreover, boehmite with 3D superstructures (e.g., stalk-like [14], cantaloupe-like [15], leaf-like [16], and flower-like [17]) has been frequently prepared through the assembly of nanofiber, nanorods, or nanosheets using the aforementioned aluminum-bearing salts or aluminum alkoxide. However, all of the aforementioned methods for preparing boehmite are carried out in homogeneous systems. A diluted solution is extensively used to avoid agglomeration of fine particles in a disorderly way as a result of the spontaneous precipitation of primary particles in concentrated solutions. Moreover, a two-stage method of precipitation of amorphorous fine $\mathrm{Al}(\mathrm{OH})_{3}$-hydrothermal preparation of $\mathrm{AlOOH}$ has often been reported [18-19], which is a complicated technology. In addition, low productivity, the use of expensive surfactants [20-21], and the generation of

Corresponding author: Zheng Li_E-mail: lizhengtctc@163.com

(C) The Author(s) 2017. This article is published with open access at link.springer.com 
highly hazardous waste water increase $\mathrm{AlOOH}$ production costs and limit the industrial application of this two-stage method.

By contrast, boehmite can be precipitated from supersaturated sodium aluminate solution through the addition of boehmite seed, reducing the energy consumed by the calcination step in metallurgical alumina production [23]. The precipitation of gibbsite or boehmite does not generate waste water and enables the low-cost preparation of sodium aluminate solution. Moreover, boehmite with a plate-like morphology is often obtained because of the predominance of $\mathrm{OH}^{-}$ions in the aluminate solution [24].

Herein, we present a simple, economical, and environmentally friendly route to precipitate boehmite with a specific morphology in a heterogeneous system. In this method, soluble gibbsite is added as a preliminary seed material and saturation modifier in solution. The fresh fine boehmite then nucleates on the gibbsite during preliminary precipitation and grows through self-assembly in the supersaturated sodium aluminate solution.

In this study, nearly spherical boehmite was precipitated from a concentrated sodium aluminate solution by the addition of gibbsite as a seed material. The surface energy of the exposed planes of the gibbsite and boehmite was calculated using the program DMol to elucidate the precipitation mechanism. The precipitation ratio, X-ray diffraction (XRD) analysis, and Fourier transform infrared spectroscopy (FTIR) analysis were also used to observe the variation of concentration and phase evolution. Scanning electron microscopy (SEM) and Transmission electron microscope (TEM) were used to analyze the change in morphology.

\section{Experimental}

\subsection{Material}

Aluminum hydroxide, sodium hydroxide (Tianjin Kermel Chemical Reagent Co., Ltd., China), and distilled water were used to prepare the supersaturated sodium aluminate solution. After the solution was twice filtered, the resultant solution was finally diluted to the given concentration for precipitation. Hydrochloric acid, sodium acetate, zinc nitrate, sodium hydroxide, and ethylenediaminetetraacetic acid for analysis were all analytically pure.

\subsection{Experimental procedure}

The boehmite was precipitated from a $100-\mathrm{mL}$ sodium aluminate solution with a caustic molar ratio $\left(\alpha_{\mathrm{k}}\right)$ of 1.41 (molar ratio of $\mathrm{Na}_{2} \mathrm{O}$ to $\mathrm{Al}_{2} \mathrm{O}_{3}$ in solution) at $180^{\circ} \mathrm{C}$ in an autoclave $(150 \mathrm{~mL})$ by adding gibbsite $\left(226 \mathrm{~g} \cdot \mathrm{L}^{-1}\right)$ as a seed material. Boehmite was obtained after the precipitate was filtered, washed with boiling water, and dried at $100^{\circ} \mathrm{C}$ for 4 h. The concentration of caustic soda $\left(\mathrm{Na}_{2} \mathrm{O}\right)$ and alumina $\left(\mathrm{Al}_{2} \mathrm{O}_{3}\right)$ in the filtrate was determined by titration after the filtrate was diluted to $1000 \mathrm{~mL}$. The gibbsite or boehmite in the dried filter cake (solid sample) was subsequently characterized by XRD, SEM, TEM, and FTIR.

\subsection{Characterization}

The precipitation ratio $(\eta)$ was calculated according to the following equation:

$\eta=\frac{\alpha_{k 1}-\alpha_{k 0}}{\alpha_{k 1}} \times 100 \%$

where $\alpha_{k 0}$ and $\alpha_{k 1}$ represent the caustic molar ratio in solution initially and at time $t$, respectively.

The precipitated solid sample and potassium bromide were mixed and pressed into a thin disk. Its FTIR spectrum was then recorded with a NICOLET 6700 Fourier transform spectrometer (Thermo Fisher Scientific, USA) over the $4000-400 \mathrm{~cm}^{-1}$ wavenumber region, with a spectral resolution of $4 \mathrm{~cm}^{-1}$.

$\mathrm{XRD}$ patterns were recorded in the $2 \theta$ range from $5^{\circ}$ to $75^{\circ}$ with a Rigaku (model TTR-III) diffractometer equipped with a $\mathrm{Cu} \mathrm{K}$ radiation source. The samples were scanned at $5^{\circ} \cdot \mathrm{min}^{-1}$. The interplanar spacing $\left(d_{(h k l)}\right)$ was estimated using the Bragg equation:

$2 d_{(h k l)} \sin \theta=\lambda$

where $\lambda(=0.154 \mathrm{~nm})$ is the wavelength of X-rays, $\theta$ and $d_{(h k l)}$ are the Bragg angle and the interplanar spacing, respectively.

The morphology of the powder sample was examined by SEM using a JSM-6360V (JEOL) microscope. To observe the morphological evolution of a particle during precipitation, samples were first fixed using epoxy resin and triethanolamine and then carefully polished; a microsection of the sample was then observed by SEM.

TEM was carried out with a Tecnai F20 (FEI) microscope. Selected-area electron diffraction (SAED) patterns and high-resolution TEM (HRTEM) were also used to analyze the samples.

\subsection{Surface energy calculations}

The surface energy of a particle is related to its growth and dissolution rate in a solution. Thus, the surface energy for various planes of boehmite or gibbsite was calculated. The space group of boehmite is $\mathrm{Cmcm}$, and the hydrogen sites are partially occupied (50\%), as presented by Corbató et al. [25]. In addition, the surface hydroxyl species exist in the form of $\mathrm{O}^{-}$in an alkaline environment.

All calculations were performed using the density func- 
tional theory method implemented in $\mathrm{DMol}^{3}$ code [26-27] with the generalized gradient approximation (GGA) [28] functional of Perdew, Burke, and Ernzerhof (PBE) [29]. The spin-restricted and spin-unrestricted algorithms were used for closed- and open-shell systems, respectively. An all-electron double-numerical basis set with polarization functions was applied for all atoms. The thickness of the vacuum slab was $1.0 \mathrm{~nm}$, and the density functional geometry was optimized by the Broyden-Fletcher-Goldfarb-Shanno method. A plane-wave cutoff energy of $300 \mathrm{eV}$ was used in the calculations, which ensured a total-energy convergence of $10^{-4} \mathrm{eV} /$ atom. The surface energy was calculated according to the following equation [30]:

$\gamma=\left[E_{\text {slab }}-\left(N_{\text {slab }} / N_{\text {bulk }}\right) E_{\text {bulk }}\right] / A$

where $E_{\text {slab }}$ and $E_{\text {bulk }}$ are the total energy of the relaxed slab and the total energy for single $\gamma-\mathrm{AlOOH}$, respectively; $N_{\text {slab }}$ and $N_{\text {bulk }}$ correspond to the total atom number of the relaxed slab and that of single $\gamma$-AlOOH bulk, respectively; and $A$ represents the surface area of the slab.

\section{Results and discussion}

\subsection{Surface energy of boehmite and gibbsite}

The surface energy of the (001), (100), (010), (011), and (110) planes for boehmite is presented in Fig. 1. The surface energy order of boehmite is $E_{\text {sur }}(010)<E_{\text {sur }}(011)<E_{\text {sur }}(110)<$ $E_{\text {sur }}(100)<E_{\text {sur }}(011)$. Obviously, the (010) plane has the lowest surface energy and, in principle, growth priority. The (011), (110), and (100) planes have increased surface energies, growing subsequently in solution. By contrast, the (001) plane is difficult to expose because it possesses the highest surface energy.

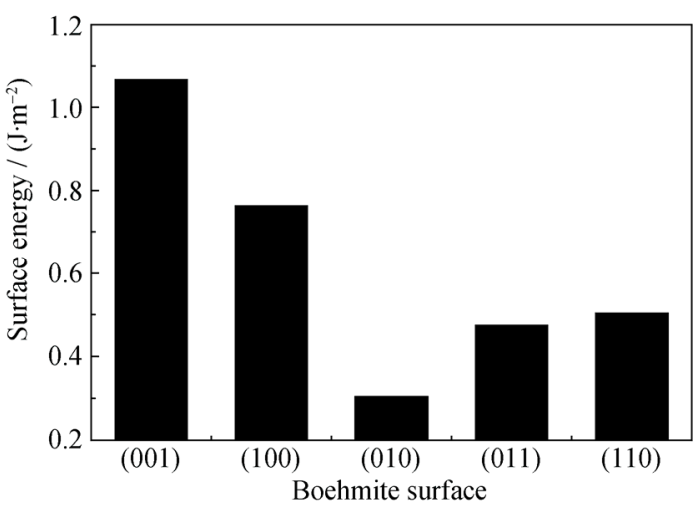

Fig. 1. Surface energy of boehmite slab models calculated using the GGA-PBE functional.

The surface energy of gibbsite was similarly calculated. The thickness vacuum slab of gibbsite was $1.5 \mathrm{~nm}$, and the geometry optimization was conducted using the GGA-PBE functional. The surface energy of gibbsite is shown in Fig. 2.

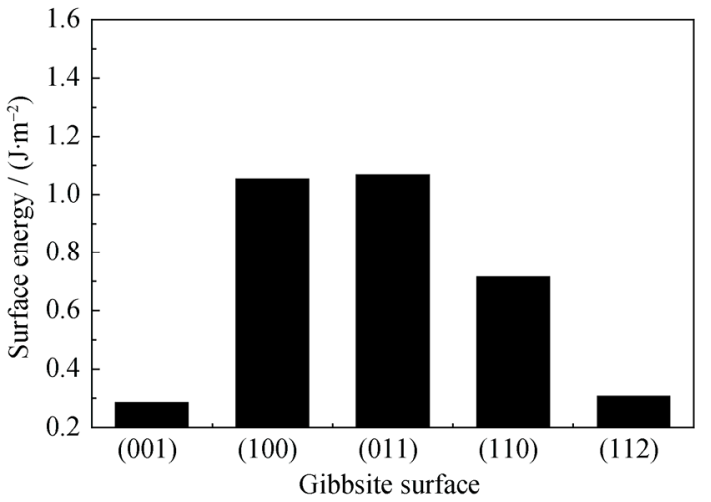

Fig. 2. Surface energy of gibbsite slab models calculated using the GGA-PBE functional.

Fig. 2 shows that the lowest surface energy is assigned to the basal (001) plane of gibbsite. Thus, the (001) plane is a preferentially exposed plane during precipitation from the sodium aluminate solution, as demonstrated in the precipitation of gibbsite from the pregnant sodium aluminate solution. The (100) and (011) planes, which have the highest surface energy, are not exposed planes but are theoretically active and preferentially dissolved in solution.

Therefore, the various planes of boehmite or gibbsite with different surface energies enable the control of their precipitation order or dissolution rate. Moreover, solubility also depends on particle size because of the various surface tensions. Thus, coarse gibbsite was used to provide an active site for boehmite to nucleate in the preliminary precipitation of boehmite.

\subsection{FTIR spectra and XRD patterns}

As the reaction time increases, the variation in the characteristic peak for boehmite is clearly observed in the FTIR spectra because these spectra distinguish between the hydroxyl species of gibbsite and boehmite, as shown in Fig. 3.

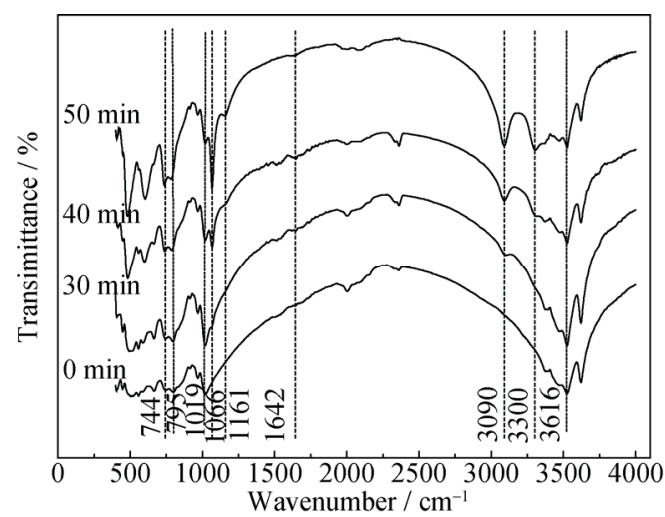

Fig. 3. FTIR spectra of the samples collected at different times during seeded precipitation (sodium aluminate solution: $\rho_{\mathrm{Na}_{2} \mathrm{O}}=44.73 \mathrm{~g} \cdot \mathrm{L}^{-1}, \alpha_{k}=1.41$; seeded precipitation conditions: $T=$ $180^{\circ} \mathrm{C}$, dosage of gibbsite seed $\left.=266 \mathrm{~g} \cdot \mathrm{L}^{-1}\right)$. The caustic soda concentration is expressed as the mass of dissolved equivalent sodium oxide per volume of solution. 
In Fig. 3, peaks at $3616 \mathrm{~cm}^{-1}$ are assigned to $\mathrm{O}-\mathrm{H}$ stretching vibrations of gibbsite [31]. In addition, peaks at 1019 and $795 \mathrm{~cm}^{-1}$ correspond to $\mathrm{O}-\mathrm{H}$ bending and $\mathrm{Al}-\mathrm{O}$ vibrations of gibbsite [32], respectively (0 min). During precipitation, the weak peak at $3090 \mathrm{~cm}^{-1}$ assigned to $\mathrm{O}-\mathrm{H}$ stretching of boehmite is observed at $30 \mathrm{~min}$, and peaks at 3300 , 1066 , and $744 \mathrm{~cm}^{-1}$ corresponding to $\mathrm{O}-\mathrm{H}$ stretching, $\mathrm{O}-\mathrm{H}$ and Al-O bond vibrations of boehmite, respectively, at 40 min are also observed [33]. Meanwhile, the intensity of the peaks assigned to gibbsite decreases with increasing precipitation time, suggesting the disappearance of gibbsite. Lastly, the well-characteristic peaks of boehmite at 3090 and $3300 \mathrm{~cm}^{-1}$ are clearly observed at $50 \mathrm{~min}$. These results all suggest that boehmite is readily precipitated from sodium aluminate solution by the addition of gibbsite as seed.

XRD patterns of the precipitates are presented in Fig. 4. To further characterize the phase evolution, the intensity variations of the XRD peaks for boehmite and gibbsite are shown in Figs. 5 and 6.

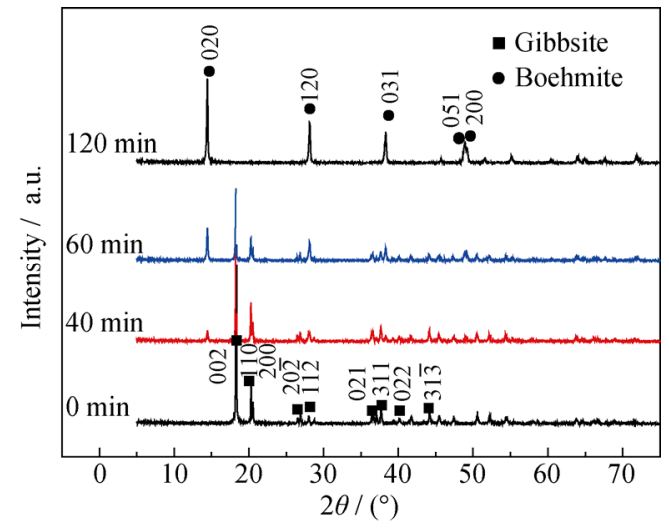

Fig. 4. XRD patterns of the precipitates collected at different precipitation times $\left(\rho_{\mathrm{Na}_{2} \mathrm{O}}=44.73 \mathrm{~g} \cdot \mathrm{L}^{-1}, \alpha_{k}=1.41, \rho_{\text {seed }}=266\right.$ $\mathrm{g} \cdot \mathbf{L}^{-1}$, and $\left.T=180^{\circ} \mathrm{C}\right)$.

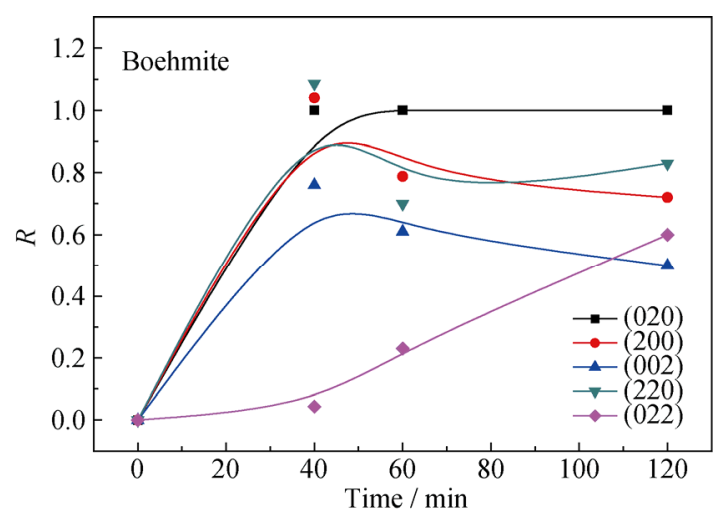

Fig. 5. Intensity variation of the XRD $(\mathrm{hkl})$ diffraction peaks of boehmite ( $R$ represents the ratio between the peak intensity in the XRD patterns of the samples and that given in the standard XRD card for the different surfaces of boehmite (PDF No. 021-1307)).

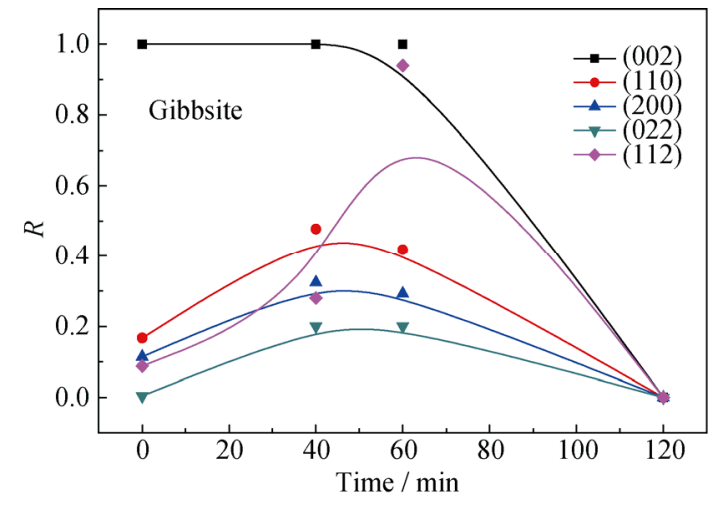

Fig. 6. Intensity variation of the XRD $(h k l)$ diffraction peaks of gibbsite ( $R$ represents the ratio between the peak intensity in the XRD patterns of the samples and that given in the standard XRD card for the different surfaces of gibbsite (PDF No. 074-1775))

The results in Fig. 4 show that the intensities of the (002), (110), (200), (20̄ ), (112), (021), (022), and (311) planes of gibbsite decrease differently for the precipitate compared to those for the gibbsite seed $(0 \mathrm{~min})$. The (002) and (112) planes are always observed within $60 \mathrm{~min}$, although their intensity gradually decreases. However, the (110) plane disappears at $40 \mathrm{~min}$. The XRD results also indicate that the (020) plane of boehmite first appears at $40 \mathrm{~min}$ and that the (120), (031), and (051) planes of boehmite appear at $60 \mathrm{~min}$. All of the peaks corresponding to boehmite are observed at $120 \mathrm{~min}$. All of these results are in accordance with the surface energy calculations. The interplanar space of boehmite for $d_{(002)}$ and $d_{(200)}$ are respectively 0.143 and $0.186 \mathrm{~nm}$, as calculated from the Bragg equation.

The ratio $R$ between the XRD peak intensity and that listed in the standard XRD card for boehmite (Fig. 5) increases rapidly in the case of the (020) plane and maintains its maximum value from 60 to $120 \mathrm{~min}$. The (020) plane is the usual exposed surface of boehmite. By contrast, the $R$ values for the (002) and (022) planes increase slowly, implying their difficult growth. In addition, each plane of boehmite is exposed at $120 \mathrm{~min}$ when pure boehmite is formed.

In the case of gibbsite, the results in Fig. 6 indicate that the usual exposed surfaces are (002) and (112) because their $R$ values maintain their maximum values after reaction for $60 \mathrm{~min}$. In addition, other planes of gibbsite may preferentially disappear because of the rapid decrease in $R$. The $R$ values for various planes are equal to zero at $120 \mathrm{~min}$, indicating that gibbsite is dissolved completely. The difference in the $R$ values of boehmite or gibbsite implies that the (020) plane of boehmite can be preferentially nucleated on the (002) and (112) planes of the gibbsite substrate. After nucleation, the (020) plane of boehmite grows vertically on the (002) and (112) planes of gibbsite via self-assembly. 


\subsection{Morphology evolution}

\subsubsection{SEM images of samples}

SEM images of the solid samples collected after different reaction times are shown in Fig. 7, directly showing the disappearance of gibbsite and the precipitation of boehmite. The morphology of gibbsite at $0 \mathrm{~min}$ is irregular. Many fine particles are attached to the coarse particle in Fig. 7(a). Fine gibbsite then disappears, and only the large particle with a smooth (001) plane remains. Meanwhile, a small, very fine flake-like particle is nucleated and generated on the (001) plane of the coarse gibbsite at $20 \mathrm{~min}$ (Fig. 7(b)). With the increase of precipitation time to $60 \mathrm{~min}$, additional flake-like particles grow vertically on gibbsite and gibbsite is hardly found (Fig. 7(c)). When the duration is $120 \mathrm{~min}$, flake-like boehmite agglomerates into nearly spherical particles. Moreover, a 3D-like architecture is obtained via the self-assembly of fine flake-like particles (Fig. 7(d)). Given the phase evolution in Fig. 4, gibbsite acts as the preliminary seed for boehmite and boehmite itself acts as seed in the later period. This condition prevents a large number of fresh primary boehmite particles from growing out of order in the concentrated solution. A small section of Fig. 7(d) is enlarged in Fig. 7(e), showing the morphology of boehmite at $120 \mathrm{~min}$. The results in Fig. 7(e) indicate that the thin flakes with a thickness of $50 \mathrm{~nm}$ and a length of 1-2 $\mu \mathrm{m}$ grow vertically and alternately.
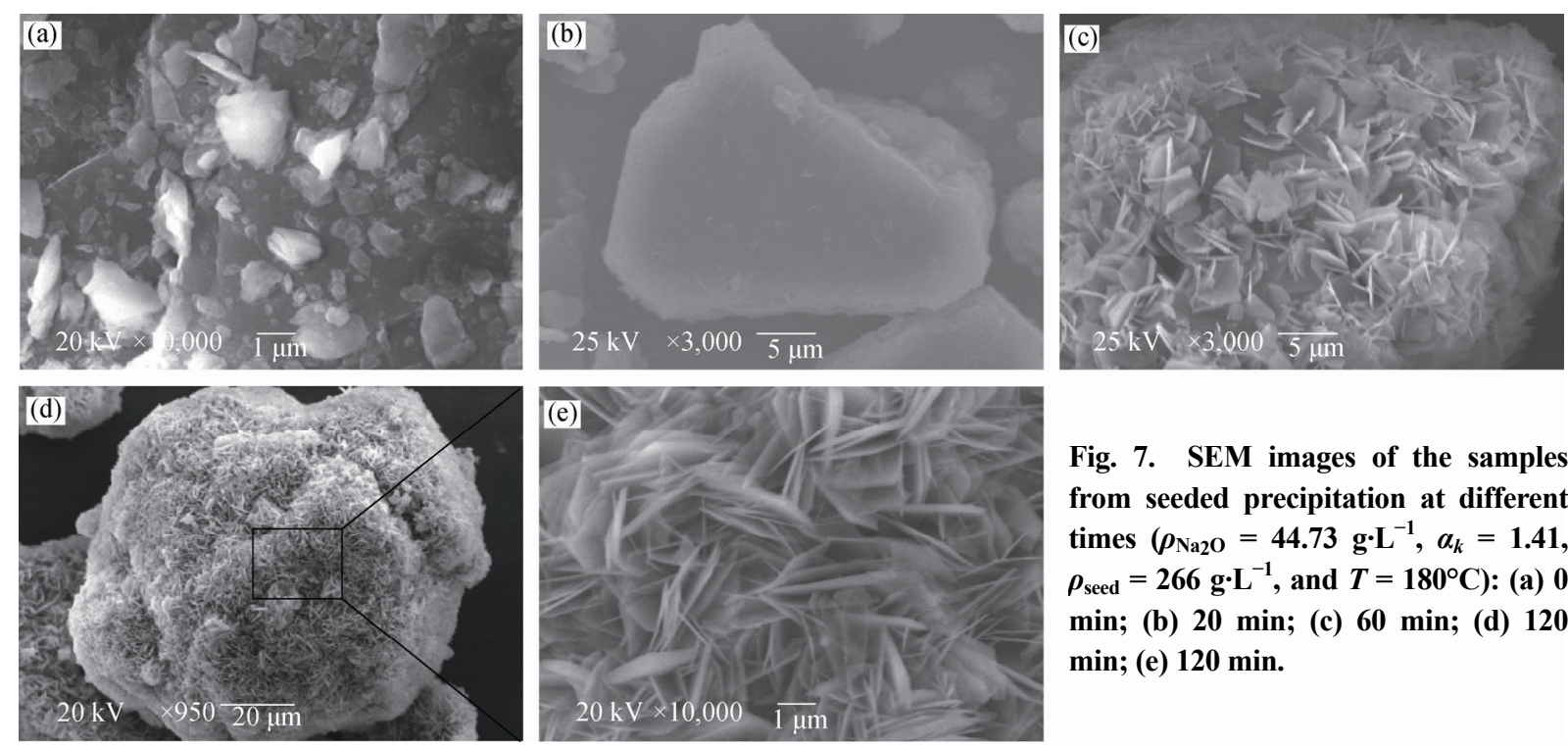

Fig. 7. SEM images of the samples from seeded precipitation at different times $\left(\rho_{\mathrm{Na}_{2} \mathrm{O}}=44.73 \mathrm{~g} \cdot \mathrm{L}^{-1}, \alpha_{k}=1.41\right.$, $\rho_{\text {seed }}=266 \mathrm{~g} \cdot \mathrm{L}^{-1}$, and $T=180^{\circ} \mathrm{C}$ ): (a) 0 min; (b) $20 \mathrm{~min}$; (c) $60 \mathrm{~min}$; (d) 120 min; (e) 120 min.

The interior variation of particles during the phase and morphology evolution is shown in the microsections of the samples in Fig. 8. The smooth surface and clear edge of gibbsite are easily observed at $0 \mathrm{~min}$. At $20 \mathrm{~min}$, a fine fragment near the edge is observed for the formation of boehmite although the smooth surface is maintained. When the precipitation time is extended to $60-90 \mathrm{~min}$, the coarse gibbsite is broken up and more flake-like boehmite particles are formed among the interfaces of the fine particles. At $120 \mathrm{~min}$, the fine flake boehmite interweaves together and distributes uniformly from the interior to the exterior. Fig. 8(f) shows that the flake-like boehmite particles are agglomerated closely instead of stacked incompactly. This observation implies that the spherical boehmite possesses high strength and a special surface area.

\subsubsection{TEM image of the sample}

TEM (Fig. 9) was used to explore variations in the mi- crostructure of the boehmite. The results in Fig. 9(a) show that the flake-like particles are boehmite. A typical SAED pattern is shown in the inset of Fig. 9(a). Indexing of the patterns indicates that boehmite possesses a crystal structure consistent with the orthorhombic form of boehmite $(\mathrm{AlOOH})$. The results in Fig. 9(b) show that the interplanar spacings of $0.185,0.112$, and $0.142 \mathrm{~nm}$ correspond to the (200), (202), and (002) planes of boehmite, respectively, in agreement with the XRD results (Fig. 4). This agreement again demonstrates that the basal (020) plane of boehmite is preferentially exposed.

\subsection{Variation of the precipitation ratio}

To investigate the precipitation mechanism of the spherical boehmite, the effect of the caustic soda $\left(\mathrm{Na}_{2} \mathrm{O}\right)$ concentration and duration on the precipitation ratio with the addition of gibbsite as seed at $180^{\circ} \mathrm{C}$ is plotted in Fig. 10. The precipitation ratio in Fig. 10, as a whole, increases with 

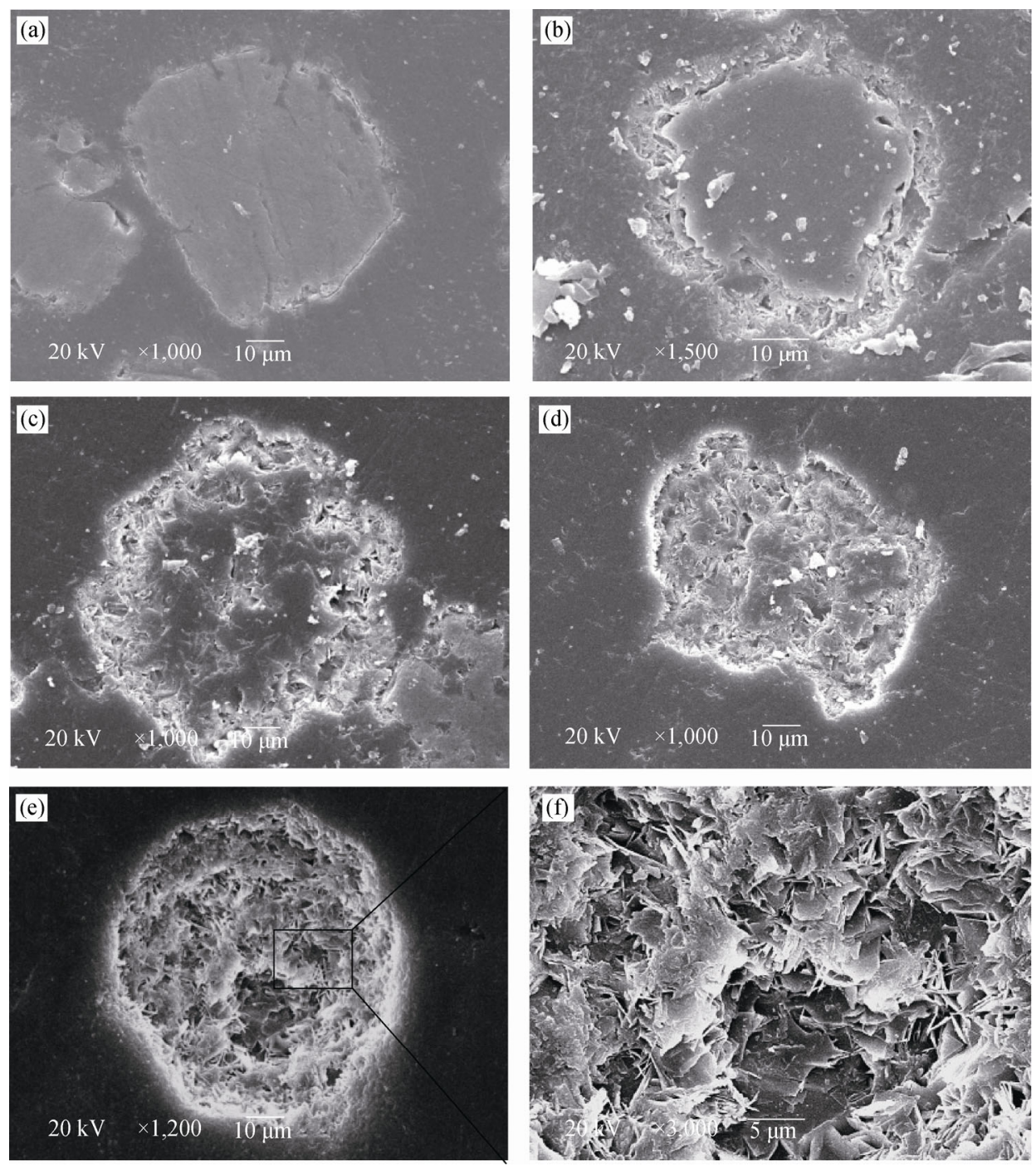

Fig. 8. SEM images of the microsection samples from seeded precipitation at different times $\left(\rho_{\mathrm{Na}_{2} \mathrm{O}}=44.73 \mathrm{~g} \cdot \mathrm{L}^{-1}, \alpha_{k}=1.41, \rho_{\text {seed }}=\right.$ $266 \mathrm{~g} \cdot \mathrm{L}^{-1}$, and $T=180^{\circ} \mathrm{C}$ ): (a) $0 \mathrm{~min}$; (b) $20 \mathrm{~min}$; (c) $30 \mathrm{~min}$; (d) $120 \mathrm{~min}$; (e) $120 \mathrm{~min}$.
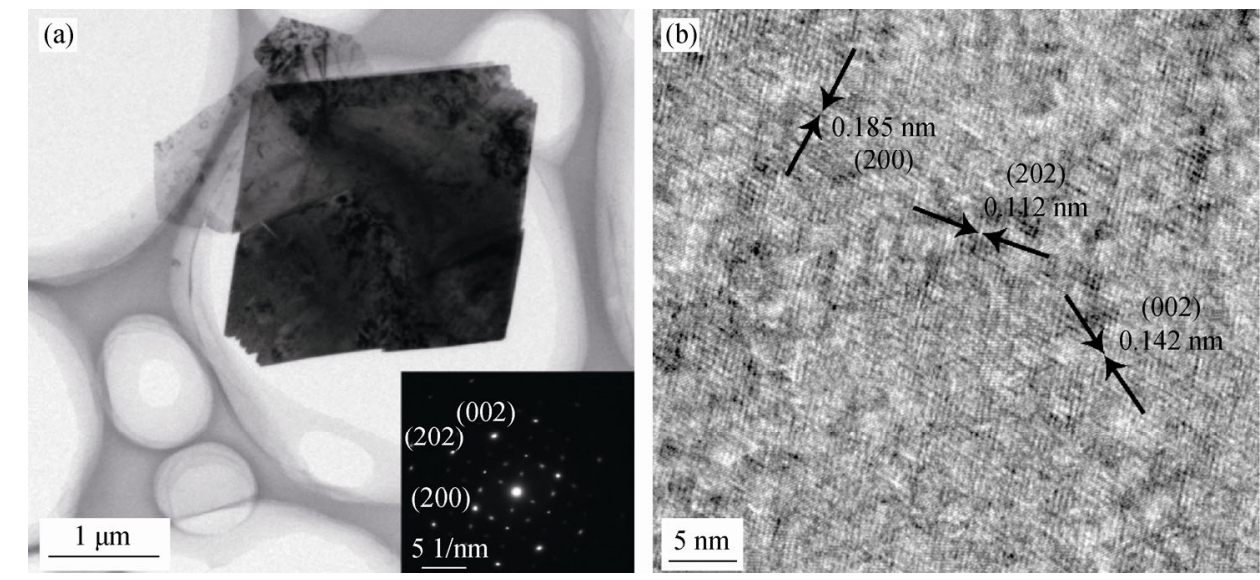

Fig. 9. TEM microphotograph (a), SAED pattern (inset in (a)) and HRTEM image (b) of the sample collected at $60 \mathrm{~min}\left(\rho_{\mathrm{Na} 2 \mathrm{O}}=\right.$ $44.73 \mathrm{~g} \cdot \mathrm{L}^{-1}, \alpha_{k}=1.41, \rho_{\text {seed }}=266 \mathrm{~g} \cdot \mathrm{L}^{-1}$, and $T=180^{\circ} \mathrm{C}$ ). 


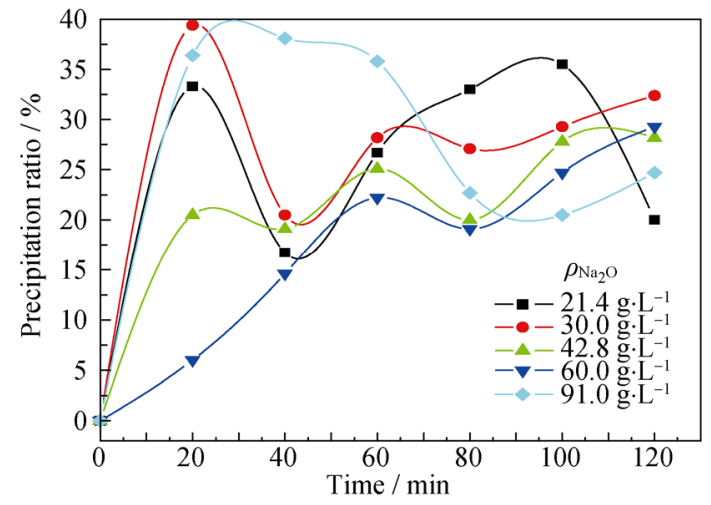

Fig. 10. Effect of caustic soda concentration and precipitation duration on the seeded precipitation ratio in sodium aluminate solution $\left(\alpha_{k}=1.41, \rho_{\text {seed }}=266 \mathrm{~g} \cdot \mathrm{L}^{-1}\right.$, and $\left.T=180^{\circ} \mathrm{C}\right)$.

increasing duration, and boehmite is readily precipitated. However, the precipitation ratio of boehmite fluctuates in the shape of an " $M$ " in different solutions. Moreover, the variation tendency of the precipitation ratio in solutions with $21.4 \leq \rho_{\mathrm{Na}_{2} \mathrm{O}} \leq 91.0 \mathrm{~g} \cdot \mathrm{L}^{-1}$ is easily observed because the gibbsite is readily dissolved, leading to rapid saturation for boehmite as compared to their solubility. Therefore, the facts can be explained by an alternate reaction between gibbsite dissolution and boehmite precipitation, wherein two reactions occur according to the following reaction equations:

$$
\begin{aligned}
& \mathrm{Al}(\mathrm{OH})_{4}^{-}=\mathrm{AlOOH}+\mathrm{H}_{2} \mathrm{O}+\mathrm{OH}^{-} \\
& \mathrm{Al}(\mathrm{OH})_{3}+\mathrm{OH}^{-}=\mathrm{Al}(\mathrm{OH})_{4}^{-}
\end{aligned}
$$

Moreover, the solubilities of gibbsite and boehmite were measured in sodium aluminate solution on the basis of a method reported in Refs. [34-35]. The effects of temperature and caustic soda concentration on the solubility of gibbsite and boehmite are shown in Fig. 11.

Fig. 11 shows that the solubilities of gibbsite and boehmite increase with increasing temperature and with increasing caustic soda concentration. The solubility of boehmite is less than that of gibbsite. In addition, the difference in solubility between gibbsite and boehmite increases with increasing temperature or increasing caustic soda concentration. This condition suggests that slightly dissolution of gibbsite and rapid precipitation of boehmite occur in the diluted solution, leading to the increase and subsequent decrease of the precipitation ratio. Boehmite initially precipitates from the diluted sodium aluminate solution with $\alpha_{k}=$ 1.41 because of the high supersaturation (Eq. (4)) and the presence of a large number of gibbsite seeds, resulting in the rapid increase of $\alpha_{k}$ and the precipitation ratio. Afterwards, the rate of boehmite precipitation decreases and gibbsite is dissolved (Eq. (5)) again because of the unsaturated solution for gibbsite and boehmite. Therefore, the alternating occur- rence of gibbsite dissolution and boehmite precipitation leads to the variation of the precipitation ratio in an "M" shape.

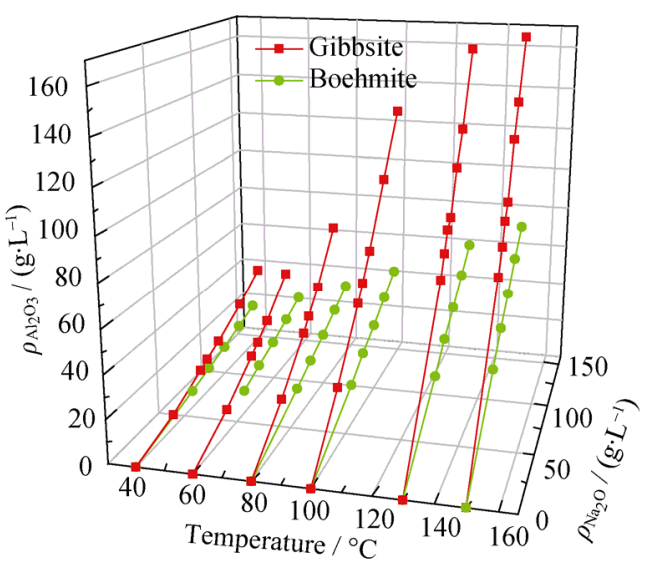

Fig. 11. Effect of temperature and caustic soda concentration on the solubilities of gibbsite and boehmite. The gibbsite and boehmite solubilities are expressed as the mass of dissolved equivalent alumina per volume of solution.

\subsection{Precipitation mechanism}

On the basis of the evolution of phase and morphology during the precipitation of the spherical boehmite, we propose the following precipitation mechanism for spherical boehmite (Fig. 12).

The different solubilities of gibbsite and boehmite are the major driving force in the precipitation of boehmite. In addition, various surface energies of gibbsite and boehmite determine the dissolution order of gibbsite particles as well as the growth rate of boehmite, leading to the precipitation of spherical boehmite via self-assembly (Fig. 12). The stable surface of the (001) and (112) planes for gibbsite provides a nucleation site for boehmite, and the fine boehmite is then nucleated. Moreover, unstable surfaces of gibbsite are preferentially dissolved in the preliminary precipitation. As the reaction duration increases, more gibbsite particles are dissolved continuously to maintain the saturation for boehmite. In addition, the preferential (020) plane of boehmite is grown vertically on the basal (001) and (112) planes of gibbsite in the form of nanoflake-like particles. Thereafter, the gibbsite is dissolved completely. The fresh boehmite itself then acts as a seed material. Boehmite grows, and various planes of boehmite are exposed in turn. Lastly, the flake-like particles agglomerate into the spherical boehmite.

Therefore, the different solubilities of gibbsite and boehmite are the key to maintaining the saturation and promoting the precipitation of boehmite. Moreover, the different surface energies of gibbsite and boehmite provide the prelimi- 
nary nucleation sites in the most energy-favorable path and then allow the growth of boehmite into flake-like particles via self-assembly before the gibbsite acts as the preliminary heterogeneous nuclei for boehmite. This unconventional method to prepare specific boehmite avoids particle nuclea- tion and disorderly growth caused by massive bursting precipitation of homogeneous fine particles. This condition provides an environmentally friendly and effective method to prepare boehmite with a specific shape without adding other inorganic cations or anions as a template.
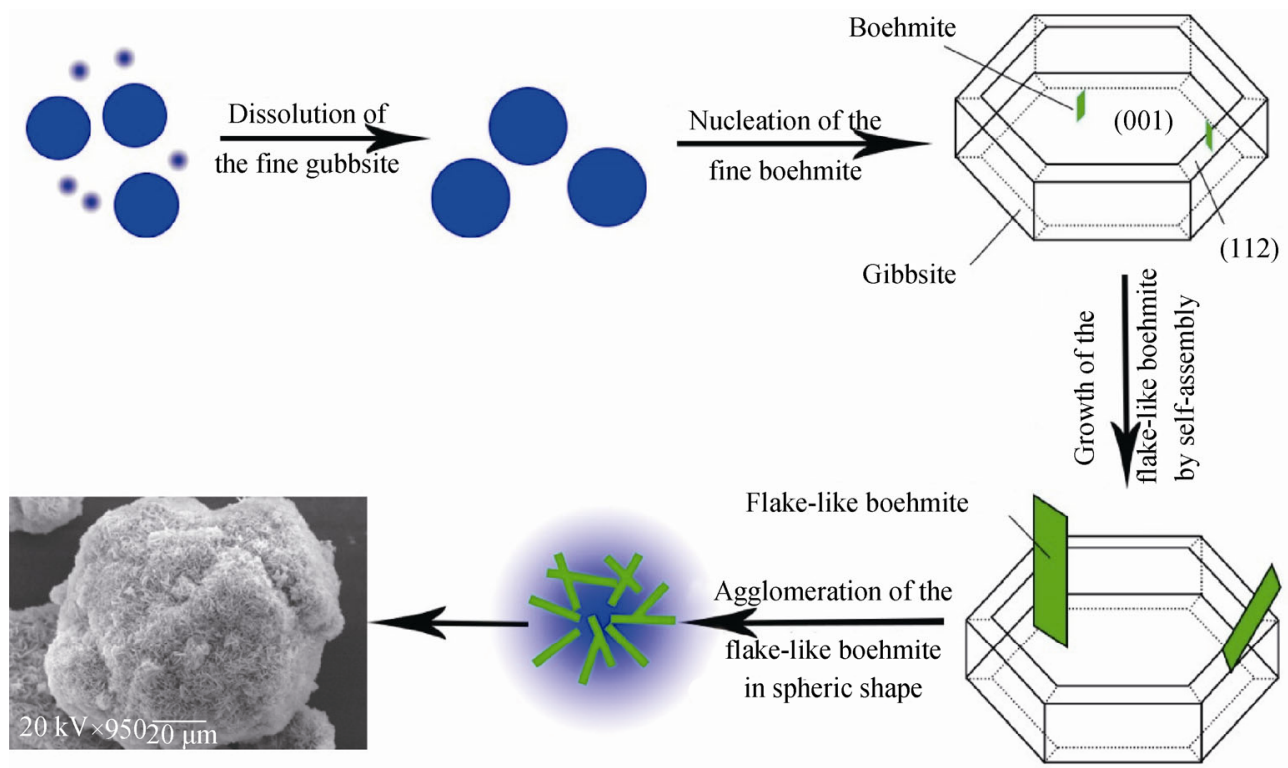

Fig. 12. Precipitation mechanism of spherical boehmite from the sodium aluminate solution.

\section{Conclusions}

(1) The surface energies of gibbsite and boehmite are different. The lowest-energy surfaces are the (010) plane for boehmite and the (001) and (112) planes for gibbsite. Moreover, the solubility and the difference in solubility of gibbsite and boehmite increase with increasing temperature and increasing caustic soda concentration.

(2) The nearly spherical boehmite with nanoflake particles formed by self-assembly is precipitated from the supersaturated sodium aluminate solution upon the addition of gibbsite as a seed at $180^{\circ} \mathrm{C}$. Fine boehmite nucleates on the (001) and (112) planes of the gibbsite seeds. More boehmite particles are formed and grow into flake-like particles with increasing precipitation time. Lastly, gibbsite is dissolved completely and the flake-like particles agglomerate into a spherical boehmite with a 3D structure.

(3) The curves of precipitation ratio fluctuate in an "M" shape because of the gibbsite dissolution and boehmite precipitation. Gibbsite dissolution maintains the saturation of boehmite precipitation and provides active sites for boehmite nucleation in the preliminary precipitation process. The difference in surface energies of boehmite allows the growth of flake-like boehmite via self-assembly, where more flake-like particles are formed from the exterior to the inte- rior, thereby creating a compact sphere.

\section{Acknowledgements}

This work was financially supported by the National Natural Science Foundation of China (No. 51274242) and the Fundamental Research Funds for the Central Universities of Central South University (No. 2016zzts038).

Open Access This article is distributed under the terms of the Creative Commons Attribution 4.0 International License (http://creativecommons.org/licenses/by/4.0/), which permits unrestricted use, distribution, and reproduction in any medium, provided you give appropriate credit to the original author(s) and the source, provide a link to the Creative Commons license, and indicate if changes were made.

\section{References}

[1] U. Nylén, J.F. Delgado, S. Järås, and M. Boutonnet, Low and high-pressure ring opening of indan over $2 \mathrm{wt} \% \mathrm{Pt}$, Ir and bi-metallic $\mathrm{Pt}_{25} \mathrm{Ir}_{75}$ /boehmite catalysts prepared from microemulsion systems, Appl. Catal. A, 262(2004), No. 2, p. 189.

[2] W. Deng, P. Bodart, M. Pruski, and B.H. Shanks, Characterization of mesoporous alumina molecular sieves synthesized 
by nonionic templating, Microporous Mesoporous Mater., 52 (2002), No. 3, p. 169.

[3] S.P. Dubey, A.D. Dwivedi, M. Sillanpää, H. Lee, Y.N. Kwon, and C. Lee, Adsorption of As (V) by boehmite and alumina of different morphologies prepared under hydrothermal conditions, Chemosphere, 169(2017), p. 99.

[4] P. Alphonse and M. Courty, Structure and thermal behavior of nanocrystalline boehmite, Thermochim. Acta, 425(2005), No. 1-2, p. 75.

[5] R.L. Price, L.G. Gutwein, L. Kaledin, F. Tepper, and T.J. Webster, Osteoblast function on nanophase alumina materials: Influence of chemistry, phase, and topography, J. Biomed. Mater. Res., 67A(2003), No. 4, p. 1284.

[6] T.J. Webster, E.L. Hellenmeyer, and R.L. Price, Increased osteoblast functions on theta + delta nanofiber alumina, Biomaterials, 26(2005), No. 9, p. 953.

[7] Y.Y. Zhao, R.L. Frost, W.N. Martens, and H.Y. Zhu, Growth and surface properties of boehmite nanofibers and nanotubes at low temperatures using a hydrothermal synthesis route, Langmuir, 23(2007), No. 19, p. 9850.

[8] Y.D. Deng, Q. Yang, G.W. Lu, and W.B. Hu, Synthesis of $\gamma-\mathrm{Al}_{2} \mathrm{O}_{3}$ nanowires through a boehmite precursor route, Ceram. Int., 36(2011), No. 6, p. 1773.

[9] Y.M. Xue, J. Lin, Y. Fan, J. Li, A. Elsanousi, X.W. Xu, D. Liu, Y. Huang, Y. Liu, F.B. Meng, J. Zou, and C.C. Tang, Synthesis and hydrogen absorption of high-specific-surface ultrafine theta- $\mathrm{Al}_{2} \mathrm{O}_{3}$ nanowires, J. Cryst. Growth, 382(2013), p. 52.

[10] T.B. He, L. Xiang, and S.L. Zhu, Different nanostructures of boehmite fabricated by hydrothermal process: effects of $\mathrm{pH}$ and anions, CrystEngComm, 11(2009), No. 7, p. 1338.

[11] S.C. Shen, Q. Chen, P.S. Chow, G.H. Tan, X.T. Zeng, Z. Wang, and R.B.H. Tan, Steam-assisted solid wet-gel synthesis of high-quality nanorods of boehmite and alumina, $J$. Phys. Chem. C, 111(2007), No. 2, p. 700.

[12] J.F. Hochepied, O. Ilioukhina, and M.H. Berger, Effect of the mixing procedure on aluminium (oxide)-hydroxide obtained by precipitation of aluminium nitrate with soda, Mater. Lett., 57(2003), No. 19, p. 2817.

[13] X.Y. Chen, Z.J. Zhang, X.L. Li, and S.W. Lee, Controlled hydrothermal synthesis of colloidal boehmite $(\gamma-\mathrm{AlOOH})$ nanorods and nanoflakes and their conversion into $\gamma-\mathrm{Al}_{2} \mathrm{O}_{3}$ nanocrystals, Solid State Commun., 145(2008), No. 7-8, p. 368.

[14] Z.F. Zhu, S. Cheng, H. Liu, X.N. Dong, and Y. Shi, Hydrothermal synthesis of hexagon nanosheets self-assembled 3D stalk-like alumina, Mater. Lett., 123( 2014), p. 258.

[15] W.Q. Cai, S.G. Chen, J.G. Yu, Y.Z. Hu, C.X. Dang, and S.H. Ma, Template-free solvothermal synthesis of hierarchical boehmite hollow microspheres with strong affinity toward organic pollutants in water, Mater. Chem. Phys., 138(2013),
No. 1, p. 167.

[16] J.X. Yang, J.J. Ma, and Y.W. Huang, Hydrothermal synthesis of monodisperse leaf-like boehmite nanosheets: transformation from irregular to regular morphology, Mater. Sci. Forum, 694(2011), p. 28.

[17] G.C. Li, Y.Q. Liu, D. Liu, L.H. Liu, and C.G. Liu, Synthesis of flower-like Boehmite (AlOOH) via a simple solvothermal process without surfactant, Mater. Res. Bull., 45(2010), No. 10, p. 1487.

[18] F. Rashidi, A.N. Kharat, A.M. Rashidi, E. Lima, V. Lara, and J.S. Valente, Fractal geometry approach to describe mesostructured boehmite and gamma-alumina nanorods, Eur. J. Inorg. Chem., 2010, No. 10, p. 1544.

[19] X. Bokhimi, A. Morales, and J.S. Valente, Sulfate ions and boehmite crystallization in a sol made with aluminum tri-sec-butoxide and 2-propanol, J. Phys. Chem. C, 111(2007), No. 1, p. 103.

[20] M.M. Amini and M. Mirzaee, Effect of solution chemistry on preparation of boehmite by hydrothermal assisted sol-gel processing of aluminum alkoxides, J. Sol-Gel Sci. Technol., 36(2005), No. 1, p. 19.

[21] M. Nguefack, A.F. Popa, S. Rossignol, and C. Kappenstein, Preparation of alumina through a sol-gel process. Synthesis, characterization, thermal evolution and model of intermediate boehmite, Phys. Chem. Chem. Phys., 5(2003), No. 19, p. 4279.

[22] S.C. Kuiry, E. Megen, S.D. Patil, S.A. Deshpande, and S. Seal, Solution-based chemical synthesis of boehmite nanofibers and alumina nanorods, J. Phys. Chem. B, 109(2005), No. 9, p. 3868.

[23] B. Dash, B.C. Tripathy, I.N. Bhattacharya, S.C. Das, C.R. Mishra, and B.K. Mishra, Precipitation of boehmite in sodium aluminate liquor, Hydrometallurgy, 95(2009), No. 3-4, p. 297.

[24] A. Alemi, Z. Hosseinpour, M. Dolatyari, and A. Bakhtiar, Boehmite $(\gamma-\mathrm{AlOOH})$ nanoparticles: Hydrothermal synthesis, characterization, $\mathrm{pH}$-controlled morphologies, optical properties, and DFT calculations, Phys. Status Solidi B, 249(2012), No. 6, p. 1264.

[25] C.E. Corbató, R.T. Tettenhorst, and G.G. Christoph, Structure refinement of deuterated boehmite, Clays Clay Miner., 33(1985), No. 1, p. 71.

[26] B. Delley, An all-electron numerical method for solving the local density functional for polyatomic molecules, J. Chem. Phys., 92(1990), No. 1, p. 508.

[27] B. Delley, From molecules to solids with the $\mathrm{DMol}^{3}$ approach, J. Chem. Phys., 113(2000), No. 18, p. 7756.

[28] D.M. Bylander and L. Kleinman, Good semiconductor band gaps with a modified local-density approximation, Phys. Rev. B, 11(1990), p. 7868.

[29] J.P. Perdew, K. Burke, and M. Ernzerhof, Generalized gra- 
dient approximation made simple, Phys. Rev. Lett., 77(1996), No. 18 , p. 3865.

[30] H. Xu, P. Reunchan, S. X. Ouyang, H. Tong, N. Umezawa, T. Kako, and J. Ye, Anatase $\mathrm{TiO}_{2}$ single crystals exposed with high-reactive $\{111\}$ facets toward efficient $\mathrm{H}_{2}$ evolution, Chem. Mater., 25(2013), No. 3, p. 405.

[31] D.H. Lee and R.A. Condrate Sr., An FTIR spectral investigation of the structural species found on alumina surfaces, Mater. Lett., 23(1995), No. 4-6, p. 241.

[32] S. Musić, Đ. Dragčević, and S. Popović, Hydrothermal crystallization of boehmite from freshly precipitated aluminum hydroxide, Mater. Lett., 40(1999), No. 6, p. 269.
[33] G. García, M. Falco, P. Crespo, S. Cabrera, and U. Sedran, Characterization and catalytic evaluation of aluminum oxides obtained by the atrane route, Catal. Today, 166(2011), No. 1, p. 60 .

[34] X.B. Li, L. Yan, Q.S. Zhou, G.H. Liu, and Z.H. Peng, Thermodynamic model for equilibrium solubility of gibbsite in concentrated $\mathrm{NaOH}$ solutions, Trans. Nonferrous Met. Soc. China, 22(2012), No. 2, p. 447.

[35] D. Panias, P. Asimidis, and I. Paspaliaris, Solubility of boehmite in concentrated sodium hydroxide solutions: model development and assessment, Hydrometallurgy, 59(2001), No. 1, p. 15. 